\title{
Article
}

\section{Best proximity point of modified Suzuki-Edelstein -Geraghty type proximal contractions}

\author{
Leta Bekere Kumssa \\ Department of Mathematics, Madda Walabu University, Bale Robe-247, Ethiopia.; letabekere@yahoo.com
}

Received: 20 October 2020; Accepted: 19 December 2020; Published: 27 December 2020.

\begin{abstract}
In this paper, we introduce the notion of modified Suzuki-Edelstein-Geraghty proximal contraction and prove the existence and uniqueness of best proximity point for such mappings. Our results extend and unify many existing results in the literature. We draw corollaries and give illustrative example to demonstrate the validity of our result.
\end{abstract}

Keywords: Best proximity point, weak P-property, Suzuki contraction, Edelstein contraction, RJ-property.

\section{Introduction and Preliminaries}

I

n 1922, Banach [1] introduced a remarkable principle, namely Banach contraction principle which asserts that every contraction self-mapping on a complete metric space has a unique fixed point. This principle plays a leading role in the development of fixed point theory. Banach's contraction principle has been generalized and extended in different directions. On his work, Edelstein [2] introduced the notion of contractive mapping and generalized Banach contraction principle. In 1973, Geraghty [3] generalized Banach's contraction principle by replacing the contraction constant by a function having certain specified properties. In 2008, Suzuki [4] introduced a new type of mapping and presented a generalization of the Banach contraction principle in which the completeness can also be characterized by the existence of a fixed point of these mappings. All these generalizations are only applicable for self-mappings.

In recent years, best proximity point theory attracted the attention of several authors. The purpose of best proximity point theory is to address a problem of finding the distance between two closed sets by using non self-mappings from one set to the other. The problem is known as the proximity point problem. Best proximity point theory analyzes the existence of an approximate solution that is optimal.

Let $A$ and $B$ be two non-empty subsets of a metric space $(X, d)$ and $T: A \rightarrow B$ is a mapping, then $d(x, T x) \geq d(A, B)$ for all $x \in A$. In general, for non self-mapping $T: A \rightarrow B$, the fixed point equation $T x=x$ may not have a solution. In this case, it is focused on the possibility of finding an element $x \in A$ that is an approximate solution such that the error $d(x, T x)$ is minimum, possibly $d(x, T x)=d(A, B)$.

A best proximity point becomes a fixed point if the underlying mapping is a self-mapping. Therefore, it can be concluded that best proximity point theorems generalize fixed point theorems in a natural way. In recent years, the existence and convergence of best proximity points is an interesting aspect of optimization theory which attracted the attention of many authors [5-9].

We recall the following notations and definitions: Let $(X, d)$ be a metric space and let $A$ and $B$ be non-empty subsets of $X$.

$$
\begin{aligned}
A_{0} & :=\{x \in A: d(x, y)=d(A, B) \text { for some } y \in B\}, \\
B_{0} & :=\{y \in B: d(x, y)=d(A, B) \text { for some } x \in A\} .
\end{aligned}
$$

We denote by $\mathcal{F}$ the class of all functions $\beta:[0, \infty) \rightarrow[0,1)$ satisfying the following condition:

$$
\beta\left(t_{n}\right) \rightarrow 1 \Longrightarrow t_{n} \rightarrow 0
$$

We denote by $\Phi$ the class of all functions $\phi:[0, \infty) \rightarrow[0, \infty)$ satisfying the following conditions:

1. $\phi$ is continuous, 
2. $\phi$ is non-decreasing, and

3. $\phi(t)=0 \Longleftrightarrow t=0$.

Definition 1. [10] Let $A$ and $B$ be two non-empty subsets of metric space $(X, d)$ and $\alpha: A \times A \rightarrow[0, \infty)$ be a function. We say that a non self-mapping $T: A \rightarrow B$ is $\alpha$-proximal admissible if, for all $x, y, u, v \in A$,

$$
\left\{\begin{array}{l}
\alpha(x, y) \geq 1 \\
d(u, T x)=d(A, B) \quad \Longrightarrow \alpha(u, v) \geq 1 . \\
d(v, T y)=d(A, B)
\end{array}\right.
$$

Definition 2. [11] Let $A$ and $B$ be two non-empty subsets of a metric space $(X, d)$ and $\alpha: A \times A \rightarrow[0, \infty)$ be a function. We say that a non self-mapping $T: A \rightarrow B$ is triangular $\alpha$-proximal admissible if, for all $x, y, z, x_{1}, x_{2}, u_{1}, u_{2} \in A$,

$$
\begin{aligned}
& \left(T_{1}\right)\left\{\begin{array}{l}
\alpha\left(x_{1}, x_{2}\right) \geq 1 \\
d\left(u_{1}, T x_{1}\right)=d(A, B) \\
d\left(u_{2}, T x_{2}\right)=d(A, B)
\end{array}\right. \\
& \left(T_{2}\right)\left\{\begin{array}{l}
\alpha(x, z) \geq 1 \\
\alpha(z, y) \geq 1
\end{array} \Longrightarrow \alpha\left(u_{1}, u_{2}\right) \geq 1,\right.
\end{aligned}
$$

Definition 3. [12] Let $A$ and $B$ be two non-empty subsets of a metric space $(X, d)$ and $A_{0} \neq \varnothing$, we say that the pair $(A, B)$ has weak $P$-property if and only if

$$
\left\{\begin{array}{l}
d\left(x_{1}, y_{1}\right)=d(A, B) \\
d\left(x_{2}, y_{2}\right)=d(A, B)
\end{array} \Longrightarrow d\left(x_{1}, x_{2}\right) \leq d\left(y_{1}, y_{2}\right)\right.
$$

for all $x_{1}, x_{2} \in A$ and $y_{1}, y_{2} \in B$.

Definition 4. [10] Let $A$ and $B$ be two non-empty subsets of a metric space $(X, d)$ and $\alpha, \eta: A \times A \rightarrow[0, \infty)$ be functions. We say that a non self-mapping $T: A \rightarrow B$ is $\alpha$-proximal admissible with respect to $\eta$ if, for all $x, y, u, v, z, w \in A$,

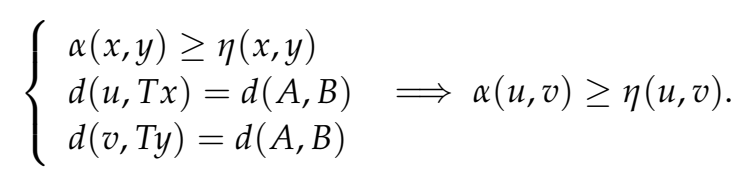

Definition 5. [13] Let $A$ and $B$ be two non-empty subsets of a metric space $(X, d)$ and $T: A \rightarrow B$ be a mapping. We say that $\mathrm{T}$ has the RJ-property if for any sequence $\left\{x_{n}\right\} \subseteq A$,

$$
\left\{\begin{array}{l}
\lim _{n \rightarrow \infty} d\left(x_{n+1}, T x_{n}\right)=d(A, B) \\
\lim _{n \rightarrow \infty} x_{n}=x
\end{array} \Longrightarrow x \in A_{0} .\right.
$$

Remark 1. [13] Any continuous mapping $T: A \rightarrow B$ has the RJ-property provided that $A$ and $B$ are non-empty closed subsets of a metric space $(X, d)$. If $A$ and $B$ are not closed subsets of $X$, then $T$ may not have RJ-property.

Example 1. [13] Let $X=\mathbb{R}, A=(0,1)$ and $B=(2,3)$. We define $d: X \times X \rightarrow[0, \infty)$ and $T: A \rightarrow B$ by $d(x, y)=|x-y|$ and $T x=3-x$. Let $\left\{x_{n}\right\}=\left\{1-\frac{1}{n}\right\} \subseteq A$, then

$$
\lim _{n \rightarrow \infty} x_{n}=1 \text { and } \lim _{n \rightarrow \infty} d\left(x_{n+1}, T x_{n}\right)=\lim _{n \rightarrow \infty} d\left(1-\frac{1}{n+1}, 2+\frac{1}{n}\right)=1=d(A, B),
$$

but $1 \notin A_{0}$. Hence $T$ does not satisfy the RJ-property. 
In 2016, Hamzehnejadi and Lashkaripour [13] proved best proximity point results for non self-map satisfying the RJ-property.

Definition 6. [13] Let $A$ and $B$ be two non-empty subsets of metric space $(X, d)$ and $\alpha: X \times X \rightarrow[0, \infty)$ be a function. A mapping $T: A \rightarrow B$ is said to be a generalized $\alpha-\phi$-Geraghty proximal contraction if there exists $\beta \in \mathcal{F}$ such that for all $x, y, u, v \in A$,

$$
\left\{\begin{array}{l}
d(u, T x)=d(A, B) \\
d(v, T y)=d(A, B)
\end{array} \quad \Longrightarrow \alpha(x, y) \phi(d(u, v)) \leq \beta(\phi(M(x, y, u, v))) \phi(M(x, y, u, v)),\right.
$$

where $M(x, y, u, v)=\max \{d(x, y), d(x, u), d(y, v)\}$ and $\phi \in \Phi$

Theorem 1. [13] Let $(X, d)$ be a complete metric space, $A$ and $B$ be non-empty subsets of $X, \alpha: X \times X \rightarrow[0, \infty)$ be a function and $T: A \rightarrow B$ be a mapping. If the following conditions are satisfied:

1. $T$ is a generalized $\alpha-\phi$-Geraghty proximal contraction type mapping,

2. $T\left(A_{0}\right) \subseteq B_{0}$ and $T$ is triangular $\alpha$ - proximal admissible,

3. Thas the RJ-property,

4. if $\left\{x_{n}\right\}$ is a sequence in $A$ such that $\alpha\left(x_{n}, x_{n+1}\right) \geq 1$ for all $n$ and $x_{n} \rightarrow x \in A$ as $n \rightarrow \infty$, then there exists a subsequence $\left\{x_{n_{k}}\right\}$ of $\left\{x_{n}\right\}$ such that $\alpha\left(x_{n_{k}}, x\right) \geq 1$ for all $k$,

5. there exist $x_{0}, x_{1} \in A$ such that $d\left(x_{1}, T x_{0}\right)=d(A, B)$ and $\alpha\left(x_{0}, x_{1}\right) \geq 1$,

then there exists $x^{*} \in A_{0}$ such that $d\left(x^{*}, T x^{*}\right)=d(A, B)$. Moreover, if $\alpha(x, y) \geq 1$ for all $x, y \in P_{T}(A)$, where $P_{T}(A)$ denotes the set of best proximity points of $T$, then $x^{*}$ is a unique best proximity point of $T$.

In this paper, we denote by $\Phi_{\varphi}$ the class of functions $\varphi:[0, \infty) \rightarrow[0, \infty)$ satisfying the following property:

$$
\varphi(t) \leq \frac{1}{2} t \text { for all } t \geq 0 .
$$

We denote by $\Psi$ the set of non-decreasing functions $\psi:[0, \infty) \rightarrow[0, \infty)$ such that

$$
\lim _{n \rightarrow \infty} \psi^{n}(t)=0 \text { for all } t \geq 0 .
$$

Recently, Hussain et al., [14] proved the existence of best proximity point for modified Suzuki-Edelstein $\alpha$-proximal contraction.

Definition 7. [14] Suppose $A$ and $B$ are two non-empty subsets of a metric space $(X, d)$. A non self-mapping $T: A \rightarrow B$ is said to be modified Suzuki-Edelstein Proximal contraction if

$$
\varphi(d(x, T x))-2 d(A, B) \leq \alpha(x, y) d(x, y) \Longrightarrow \alpha(x, y) d(T x, T y) \leq \psi(d(x, y)),
$$

for all $x, y \in A$, where $\varphi \in \Phi_{\varphi}, \psi \in \Psi$ and $\alpha: A \times A \rightarrow[0, \infty)$.

Theorem 2. [14] Suppose $A$ and $B$ are two non-empty closed subsets of a complete metric space $(X, d)$ with $A_{0}$ is non-empty and let $T: A \rightarrow B$ with $T\left(A_{0}\right) \subseteq B_{0}$ be continuous modified Suzuzi-Edelstein proximal admissible mapping with respect to $\eta(x, y)=2$ and the pair $(A, B)$ satisfies the weak P-property. If, the elements $x_{0}$ and $x_{1}$ with $d\left(x_{1}, T x_{0}\right)=$ $d(A, B)$ satisfies $\alpha\left(x_{0}, x_{1}\right) \geq 2$, then $T$ has a unique best proximity point.

Lemma 1. [15] Suppose $(X, d)$ is a metric space and $\left\{x_{n}\right\}$ be a sequence in $X$ such that $d\left(x_{n}, x_{n+1}\right) \rightarrow 0$ as $n \rightarrow \infty$. If $\left\{x_{n}\right\}$ is not a Cauchy sequence, then there exist an $\epsilon>0$ and sequences of positive integers $\left\{m_{k}\right\}$ and $\left\{n_{k}\right\}$ with $m_{k}>n_{k}>k$ such that $d\left(x_{m_{k}}, x_{n_{k}}\right) \geq \epsilon, d\left(x_{m_{k}-1}, x_{n_{k}}\right)<\epsilon$ and
(i) $\lim _{k \rightarrow \infty} d\left(x_{m_{k}-1}, x_{n_{k}+1}\right)=\epsilon$
(ii) $\lim _{k \rightarrow \infty} d\left(x_{m_{k}}, x_{n_{k}}\right)=\epsilon$
(iii) $\lim _{k \rightarrow \infty} d\left(x_{m_{k}-1}, x_{n_{k}}\right)=\epsilon$
(iv) $\lim _{k \rightarrow \infty} d\left(x_{m_{k}}, x_{n_{k}+1}\right)=\epsilon$. 
Motivated by the work of Suzuki, Edelstein and Geraghty, we introduce the notion of modified Suzuki-Edelstein-Geraghty proximal contraction and prove the existence and uniqueness of best proximity point for such mappings.

\section{Main results}

Definition 8. Let $A$ and $B$ be two non-empty subsets of metric space $(X, d)$. Let $T: A \rightarrow B$ be non self-mapping and $\alpha: A \times A \rightarrow[0, \infty)$ be a function. $T$ is said to be a modified Suzuki-Edelstein-Geraghty proximal contraction if there exist $\beta \in \mathcal{F}$ and $\phi \in \Phi$ such that for all $x, y \in A$,

$$
\begin{aligned}
& \varphi(d(x, T x))-2 d(A, B) \leq \alpha(x, y) d(x, y) \\
& \alpha(x, y) \phi(d(T x, T y)) \leq \beta(\phi(M(x, y))) \phi(\max \{d(x, y), m(x, y)-d(A, B)\}),
\end{aligned}
$$

where $M(x, y)=\max \{d(x, y), d(x, T x), d(y, T y)\}, m(x, y)=\max \{d(x, T x), d(y, T y)\}$ and $\varphi \in \Phi_{\varphi}$.

Theorem 3. Let $(X, d)$ be a complete metric space and $A$ and $B$ be non-empty closed subsets of $X$ with $A_{0}$ is non-empty. If $T: A \rightarrow B$ be a modified Suzuki-Edelstein-Geraghty proximal contraction mapping such that the following conditions hold:

1. $T\left(A_{0}\right) \subseteq B_{0}$ and the pair $(A, B)$ satisfies the weak P-property,

2. $T$ is triangular $\alpha$-proximal admissible with respect to $\eta(x, y)=2$,

3. $T$ is continuous,

4. there exist $x_{0}, x_{1} \in A$ such that $d\left(x_{1}, T x_{0}\right)=d(A, B)$ and $\alpha\left(x_{0}, x_{1}\right) \geq 2$,

then $T$ has a unique best proximity point in $A_{0}$.

Proof. By assumption (iv), there exist $x_{0}, x_{1} \in A$ such that

$$
d\left(x_{1}, T x_{0}\right)=d(A, B) \text { and } \alpha\left(x_{0}, x_{1}\right) \geq 2 .
$$

Since $T x_{0} \in B$, by the definition of $A_{0}$, from (2), we have $x_{1} \in A_{0}$. Since $T\left(A_{0}\right) \subseteq B_{0}$, we have $T x_{1} \in B_{0}$. Hence by definition of $B_{0}$, there exists an element $x_{2} \in A$ such that

$$
d\left(x_{2}, T x_{1}\right)=d(A, B) .
$$

Since $T$ is $\alpha$-proximal admissible with respect to $\eta(x, y)=2$, we obtain $\alpha\left(x_{1}, x_{2}\right) \geq 2$. On continuing this process, we have

$$
d\left(x_{n+1}, T x_{n}\right)=d(A, B) \text { and } \alpha\left(x_{n}, x_{n+1}\right) \geq 2,
$$

for all $n \in \mathbb{N}$.

Now,

$$
\begin{aligned}
\varphi\left(d\left(x_{n-1}, T x_{n-1}\right)\right) & \leq \frac{1}{2} d\left(x_{n-1}, T x_{n-1}\right) \leq 2 d\left(x_{n-1}, T x_{n-1}\right) \leq 2\left(d\left(x_{n-1}, x_{n}\right)+d\left(x_{n}, T x_{n-1}\right)\right) \\
& =2\left(d\left(x_{n-1}, x_{n}\right)+d(A, B)\right)=2 d\left(x_{n-1}, x_{n}\right)+2 d(A, B) .
\end{aligned}
$$

From (5), we have

$$
\varphi\left(d\left(x_{n-1}, T x_{n-1}\right)\right)-2 d(A, B) \leq 2 d\left(x_{n-1}, x_{n}\right) \leq \alpha\left(x_{n-1}, x_{n}\right) d\left(x_{n-1}, x_{n}\right) .
$$

By (1), it follows that

$$
\begin{aligned}
\phi\left(d\left(x_{n}, x_{n+1}\right)\right) & =\phi\left(d\left(T x_{n-1}, T x_{n}\right)\right) \leq \alpha\left(x_{n-1}, x_{n}\right) \phi\left(d\left(T x_{n-1}, T x_{n}\right)\right) \\
& \leq \beta\left(\phi\left(M\left(x_{n-1}, x_{n}\right)\right)\right) \phi\left(\max \left\{d\left(x_{n-1}, x_{n}\right), m\left(x_{n-1}, x_{n}\right)-d(A, B)\right\}\right),
\end{aligned}
$$

where $M\left(x_{n-1}, x_{n}\right)=\max \left\{d\left(x_{n-1}, x_{n}\right), d\left(x_{n-1}, T x_{n-1}\right), d\left(x_{n}, T x_{n}\right)\right\}=\max \left\{d\left(x_{n-1}, x_{n}\right), d\left(x_{n-1}, x_{n}\right), d\left(x_{n}, x_{n+1}\right)\right\}$, and $m\left(x_{n-1}, x_{n}\right)=\max \left\{d\left(x_{n-1}, T x_{n-1}\right), d\left(x_{n}, T x_{n}\right)\right\}=\max \left\{d\left(x_{n-1}, x_{n}\right), d\left(x_{n}, x_{n+1}\right)\right\}$. 
Suppose $x_{n_{0}}=x_{n_{0}+1}$ for some $n_{0} \in \mathbb{N}$. Assume that $x_{n_{0}+1} \neq x_{n_{0}+2}$, then by (6), it follows that

$$
\begin{aligned}
\phi\left(d\left(x_{n_{0}+1}, x_{n_{0}+2}\right)\right) & \leq \beta\left(\phi\left(M\left(x_{n_{0}}, x_{n_{0}+1}\right)\right)\right) \phi\left(\max \left\{m\left(x_{n_{0}}, x_{n_{0}+1}\right)-d(A, B)\right\}\right) \\
& <\phi\left(\left\{\max \left\{m\left(x_{n_{0}}, x_{n_{0}+1}\right)-d(A, B)\right\}\right)\right. \\
& \left.=\phi\left(\max \left\{d\left(x_{n_{0}}, x_{n_{0}+1}\right), d\left(x_{n_{0}+1}, x_{n_{0}+2}\right)\right\}-d(A, B)\right\}\right) \\
& \leq \phi\left(\left\{d\left(x_{n_{0}+1}, x_{n_{0}+2}\right)+d(A, B)\right\}-d(A, B)\right) \\
& =\phi\left(d\left(x_{n_{0}+1}, x_{n_{0}+2}\right)\right)
\end{aligned}
$$

a contradiction. Therefore $x_{n_{0}+1}=x_{n_{0}+2}$, hence $x_{n_{0}}=x_{n_{0}+1}=x_{n_{0}+2}$, so from (4), it follows that $d\left(x_{n_{0}}, T x_{n_{0}}\right)=$ $d\left(x_{n_{0}+1}, T x_{n_{0}}\right)=d(A, B)$, i.e., $x_{n_{0}}$ is a best proximity point of $T$, which is the desired result. Therefore, we assume that $x_{n} \neq x_{n+1}$ for all $n \in \mathbb{N} \cup\{0\}$. From (6), we obtain

$$
\begin{aligned}
\phi\left(d\left(x_{n}, x_{n+1}\right)\right) & =\phi\left(d\left(T x_{n-1}, T x_{n}\right)\right) \\
& \leq \beta\left(\phi\left(M\left(x_{n-1}, x_{n}\right)\right)\right) \phi\left(\max \left\{m\left(x_{n-1}, x_{n}\right)-d(A, B)\right\}\right) \\
& <\phi\left(\max \left\{d\left(x_{n-1}, x_{n}\right), \max \left\{m\left(x_{n-1}, x_{n}\right)\right\}-d(A, B)\right\}\right) \\
& =\phi\left(\max \left\{d\left(x_{n-1}, x_{n}\right), \max \left\{d\left(x_{n-1}, x_{n}\right), d\left(x_{n}, x_{n+1}\right)\right\}-d(A, B)\right\}\right) \\
& \leq \phi\left(\max \left\{d\left(x_{n-1}, x_{n}\right), \max \left\{d\left(x_{n-1}, x_{n}\right)+d(A, B), d\left(x_{n}, x_{n+1}\right)+d(A, B)\right\}-d(A, B)\right\}\right) \\
& =\phi\left(\max \left\{d\left(x_{n-1}, x_{n}\right), d\left(x_{n}, x_{n+1}\right)\right\}\right) .
\end{aligned}
$$

If $\max \left\{d\left(x_{n-1}, x_{n}\right), d\left(x_{n}, x_{n+1}\right)\right\}=d\left(x_{n}, x_{n+1}\right)$, then $\phi\left(d\left(x_{n}, x_{n+1}\right)\right)<\phi\left(d\left(x_{n}, x_{n+1}\right)\right)$, a contradiction. Hence $\max \left\{d\left(x_{n-1}, x_{n}\right), d\left(x_{n}, x_{n+1}\right)\right\}=d\left(x_{n-1}, x_{n}\right)$, so, by (7), we have $\phi\left(d\left(x_{n}, x_{n+1}\right)\right)<\phi\left(d\left(x_{n-1}, x_{n}\right)\right)$. By the non-decreasing property of $\phi$, it follows that $d\left(x_{n}, x_{n+1}\right) \leq d\left(x_{n-1}, x_{n}\right)$, for all $n \geq 1$. Hence we deduce that $\left\{d\left(x_{n}, x_{n+1}\right)\right\}$ is a decreasing sequence of non-negative real numbers. So, there exists $r \geq 0$ such that

$$
\lim _{n \rightarrow \infty} d\left(x_{n}, x_{n+1}\right)=r
$$

Suppose that $r>0$. From (7), we have

$$
0<\frac{\phi\left(d\left(x_{n}, x_{n+1}\right)\right)}{\phi\left(d\left(x_{n-1}, x_{n}\right)\right.} \leq \beta\left(\phi\left(M\left(x_{n-1}, x_{n}\right)\right)\right)<1,
$$

where

$$
M\left(x_{n-1}, x_{n}\right)=\max \left\{d\left(x_{n-1}, x_{n}\right), d\left(x_{n-1}, x_{n}\right), d\left(x_{n}, x_{n+1}\right)\right\}=d\left(x_{n-1}, x_{n}\right) .
$$

On letting $n \rightarrow \infty$ in (9) and using (10), we obtain $\lim _{n \rightarrow \infty} \beta\left(\phi\left(d\left(x_{n-1}, x_{n}\right)\right)\right)=1$. Since $\beta \in \mathcal{F}$, it follows that $\lim _{n \rightarrow \infty} \phi\left(d\left(x_{n-1}, x_{n}\right)\right)=0$. By continuity of $\phi$, we get

$$
\phi\left(\lim _{n \rightarrow \infty} d\left(x_{n}, x_{n+1}\right)\right)=0,
$$

i.e., $\phi(r)=0$, so that $r=0$. i.e.,

$$
\lim _{n \rightarrow \infty} d\left(x_{n}, x_{n+1}\right)=0
$$

Now, we show that $\left\{x_{n}\right\}$ is a Cauchy sequence. Suppose $\left\{x_{n}\right\}$ is not a Cauchy sequence. Then there exists an $\epsilon>0$ for which we can find sequences of positive integers $\left\{m_{k}\right\}$ and $\left\{n_{k}\right\}$ with $m_{k}>n_{k}>k$ such that

$$
d\left(x_{m_{k}}, x_{n_{k}}\right) \geq \epsilon \text { and } d\left(x_{m_{k}-1}, x_{n_{k}}\right)<\epsilon .
$$

Since $T$ is triangular $\alpha$-proximal admissible with respect to $\eta(x, y)=2$, we can show that $\alpha\left(x_{n}, x_{m}\right) \geq 2$ for all $n, m \in \mathbb{N}$ with $n<m$. If $n=m+1$, we have

$$
\alpha\left(x_{n}, x_{m}\right) \geq 2
$$


Suppose that $\alpha\left(x_{n}, x_{m}\right) \geq 2$ for all $n, m \in \mathbb{N}$ with $n<m$. To show this we shall prove that $\alpha\left(x_{n}, x_{m+1}\right) \geq 2$ with $n<m$. From (4), we have

$$
\alpha\left(x_{m}, x_{m+1}\right) \geq 2 .
$$

Also since $T$ is triangular $\alpha$-proximal admissible with respect to $\eta(x, y)=2$, then from (14) and (15), $\alpha\left(x_{n}, x_{m+1}\right) \geq 2$ for all $n, m \in \mathbb{N}$ with $n<m$. Hence for any $m_{k}, n_{k} \in \mathbb{N}$ with $n_{k}<m_{k}$, we get $\alpha\left(x_{m_{k}}, x_{n_{k}}\right) \geq 2$. From (12) and (13), we can choose a positive integer $k_{1} \in \mathbb{N}$ such that

$$
\begin{aligned}
\varphi\left(d\left(x_{m_{k}}, T x_{m_{k}}\right)\right) & \leq \frac{1}{2} d\left(x_{m_{k}}, T x_{m_{k}}\right)=\frac{1}{2} d\left(x_{m_{k}}, x_{m_{k+1}}\right) \leq \frac{1}{2} \epsilon \leq \frac{1}{2} d\left(x_{m_{k}}, x_{n_{k}}\right) \leq 2 d\left(x_{m_{k}}, x_{n_{k}}\right) \\
& \leq 2\left(d\left(x_{m_{k}}, T x_{n_{k-1}}\right)+d\left(T x_{n_{k-1}}, x_{n_{k}}\right)\right) \leq 2 d\left(x_{m_{k}}, x_{n_{k}}\right)+2 d(A, B) .
\end{aligned}
$$

From (16), we have that $\varphi\left(d\left(x_{m_{k}}, T x_{m_{k}}\right)\right)-2 d(A, B) \leq 2 d\left(x_{m_{k}}, x_{n_{k}}\right) \leq \alpha\left(x_{m_{k}}, x_{n_{k}}\right) d\left(x_{m_{k}}, x_{n_{k}}\right)$. Therefore,

$$
\varphi\left(d\left(x_{m_{k}}, T x_{m_{k}}\right)\right)-2 d(A, B) \leq \alpha\left(x_{m_{k}}, x_{n_{k}}\right) d\left(x_{m_{k}}, x_{n_{k}}\right) .
$$

By (1), we get

$$
\begin{aligned}
\phi\left(d\left(x_{m_{k+1}}, x_{n_{k+1}}\right)\right) & \leq \alpha\left(x_{m_{k}}, x_{n_{k}}\right) \phi\left(d\left(x_{m_{k+1}}, x_{n_{k+1}}\right)\right) \\
& \leq \beta\left(\phi\left(M\left(x_{m_{k}}, x_{n_{k}}\right)\right)\right) \phi\left(\max \left\{d\left(x_{m_{k}}, x_{n_{k}}\right), \max \left\{m\left(x_{m_{k}}, x_{n_{k}}\right)\right\}-d(A, B)\right\}\right),
\end{aligned}
$$

where

$$
\begin{aligned}
\max \left\{d\left(x_{m_{k}}, x_{n_{k}}\right)\right. & \left., \max \left\{m\left(x_{m_{k}}, x_{n_{k}}\right)\right\}-d(A, B)\right\} \\
& =\max \left\{d\left(x_{m_{k}}, x_{n_{k}}\right), \max \left\{d\left(x_{m_{k}}, T x_{m_{k}}\right), d\left(x_{n_{k}}, T x_{n_{k}}\right)\right\}-d(A, B)\right\} \\
& =\max \left\{d\left(x_{m_{k}}, x_{n_{k}}\right), \max \left\{d\left(x_{m_{k}}, x_{m_{k+1}}\right), d\left(x_{n_{k}}, x_{n_{k+1}}\right)\right\}-d(A, B)\right\} \\
& \leq \max \left\{d\left(x_{m_{k}}, x_{n_{k}}\right), \max \left\{d\left(x_{m_{k}}, x_{m_{k+1}}\right)+d(A, B), d\left(x_{n_{k}}, x_{n_{k+1}}\right)+d(A, B)\right\}-d(A, B)\right\} \\
& =\max \left\{d\left(x_{m_{k}}, x_{n_{k}}\right), d\left(x_{m_{k}}, x_{m_{k+1}}\right), d\left(x_{n_{k}}, x_{n_{k+1}}\right)\right\} .
\end{aligned}
$$

Hence by applying Lemma 1

$\lim _{k \rightarrow \infty} \max \left\{d\left(x_{m_{k}}, x_{n_{k}}\right), \max \left\{m\left(x_{m_{k}}, x_{n_{k}}\right)\right\}-d(A, B)\right\} \leq \lim _{k \rightarrow \infty} \max \left\{d\left(x_{m_{k}}, x_{n_{k}}\right), d\left(x_{m_{k}}, x_{m_{k+1}}\right), d\left(x_{n_{k}}, x_{n_{k+1}}\right)\right\}=\epsilon$.

On letting $k \rightarrow \infty$ in (18), it follows that

$$
0<\frac{\phi(\epsilon)}{\phi(\epsilon)} \leq \lim _{k \rightarrow \infty} \beta\left(\phi\left(M\left(x_{m_{k}}, x_{n_{k}}\right)\right)\right) \leq 1
$$

thus,

$$
\lim _{k \rightarrow \infty} \beta\left(\phi\left(M\left(x_{m_{k}}, x_{n_{k}}\right)\right)\right)=1
$$

Since $\beta \in \mathcal{F}$, we have

$$
\lim _{k \rightarrow \infty} \phi\left(\max \left\{d\left(x_{n_{k}}, x_{m_{k}}\right), d\left(x_{m_{k}}, x_{m_{k+1}}\right), d\left(x_{n_{k}}, x_{n_{k+1}}\right)\right\}\right)=0 .
$$

This yields, by continuity of $\phi$, that

$$
\phi\left(\lim _{k \rightarrow \infty}\left(\max \left\{d\left(x_{n_{k}}, x_{m_{k}}\right), d\left(x_{m_{k}}, x_{m_{k+1}}\right), d\left(x_{n_{k}}, x_{n_{k+1}}\right)\right\}\right)\right)=0,
$$

i.e., $\phi(\epsilon)=0$ and hence $\epsilon=0$, a contradiction. Hence $\left\{x_{n}\right\}$ is a Cauchy sequence. By the completeness of $X$ and closed property of $A$, there exists $x^{*} \in A$ such that $\lim _{n \rightarrow \infty} x_{n}=x^{*}$. Since $T$ is continuous, from (4), we obtain

$$
d(A, B)=\lim _{n \rightarrow} d\left(x_{n+1}, T x_{n}\right)=d\left(x^{*}, T x^{*}\right),
$$

hence $x^{*}$ is the best proximity point of $T$. 
We now show the uniqueness of best proximity point. Suppose that $u$ and $v$ are the two distinct best proximity points of $T$. Since $d(u, T u)=d(A, B)=d(v, T v)$, by weak $P$-property of the pair $(A, B)$, we get

$$
d(u, v) \leq d(T u, T v) .
$$

Now, we consider

$$
\varphi(d(u, T u)) \leq \frac{1}{2} d(u, T u) \leq 2 d(u, T u)=2 d(A, B) .
$$

From (20), we have that

$$
\varphi(d(u, T u))-2 d(A, B) \leq 0 \leq \alpha(u, v) d(u, v) .
$$

By (1) and (19), it follows that

$$
\begin{aligned}
\phi(d(u, v)) & \leq \phi(d(T u, T v)) \leq \alpha(u, v) \phi(d(T u, T v)) \\
& \leq \beta(\phi(M(u, v))) \phi(\max \{d(u, v), \max \{m(u, v)\}-d(A, B)\}) \\
& <\phi(\max \{d(u, v), \max \{m(u, v)\}-d(A, B)\}) \\
& =\phi(\max \{d(u, v), \max \{d(u, T u), d(v, T v)\}-d(A, B)\}) \\
& =\phi(d(u, v)),
\end{aligned}
$$

a contradiction. Hence $u=v$.

Example 2. Let $X=\mathbb{R}^{2}, A=[0, \infty) \times\{1\}, B=[0, \infty) \times\{0\}, A_{0}=[0,1] \times\{1\}$ and $B_{0}=[0,1] \times\{0\}$. We define $d$ by $d\left(\left(x_{1}, x_{2}\right),\left(y_{1}, y_{2}\right)\right)=\sqrt{\left(x_{1}-y_{1}\right)^{2}+\left(x_{2}-y_{2}\right)^{2}}$ for all $\left(x_{1}, x_{2}\right),\left(y_{1}, y_{2}\right) \in X$ and a map $T: A \rightarrow B$ by

$$
T(x, 1)= \begin{cases}\left(\frac{1}{2} x, 0\right) & \text { if } x \in[0,1] \\ \left(\frac{3}{2} x-1,0\right) & \text { if } x \geq 1 .\end{cases}
$$

We also define functions $\alpha: A \times A \rightarrow[0, \infty), \beta:[0, \infty) \rightarrow[0,1)$, and $\phi:[0, \infty) \rightarrow[0, \infty)$ by

$$
\begin{aligned}
\alpha((p, q),(r, s)) & = \begin{cases}2 & \text { if }(p, q),(r, s) \in[0,1] \times\{1\} \\
0 & \text { otherwise }\end{cases} \\
\beta(t) & = \begin{cases}0 & \text { if } t=0 \\
\frac{1+t}{1+2 t} & \text { if } t>0\end{cases}
\end{aligned}
$$

and

$$
\phi(t)= \begin{cases}\frac{1}{2} t & \text { if } t \in[0,1] \\ \frac{t}{1+t} & \text { if } t \geq 1\end{cases}
$$

Clearly, $T\left(A_{0}\right) \subseteq B_{0}, d(A, B)=1$ and $T$ is continuous. We choose $x_{0}=\left(\frac{1}{2}, 1\right)$ and $x_{1}=\left(\frac{1}{4}, 1\right)$ such that $d\left(x_{1}, T x_{0}\right)=d(A, B)$ and $\alpha\left(x_{0}, x_{1}\right) \geq 2$. Now, let $(x, 1),(y, 1),(u, 1),(v, 1) \in A$ such that

$$
\left\{\begin{array}{l}
\alpha((x, 1),(y, 1)) \geq 2 \\
d((u, 1), T(x, 1))=d(A, B)=1 \\
d((v, 1), T(y, 1))=d(A, B)=1
\end{array}\right.
$$

From (21), we obtain $x, y \in[0,1], u=\frac{1}{2} x \in\left[0, \frac{1}{2}\right], v=\frac{1}{2} y \in\left[0, \frac{1}{2}\right]$ and hence $d((u, 1),(v, 1)) \leq$ $d(T(x, 1), T(y, 1))$. Therefore, the pair $(A, B)$ satisfies the weak $P$-property. Also, $\alpha((u, 1),(v, 1)) \geq 2$. Hence $T$ is $\alpha$-proximal admissible. Clearly, $T$ is a triangular $\alpha$-proximal admissible with respect to $\eta((x, 1),(y, 1))=2$. 
Now, we show that $T$ is a modified Suzuki-Edelstein-Geraghty proximal contraction mapping. Let $(x, 1),(y, 1) \in[0,1] \times\{1\}$, then $\alpha((x, 1),(y, 1))=2$. Without loss of generality assume that $x>y$. Now, we consider

$$
\begin{aligned}
\max & \{d((x, 1),(y, 1)), \max \{m((x, 1),(y, 1))\}-d(A, B)\} \\
& =\max \{d((x, 1),(y, 1)), \max \{d((x, 1), T(x, 1)), d((y, 1), T(y, 1))\}-d(A, B)\} \\
& =\max \left\{d((x, 1),(y, 1)), \max \left\{d\left((x, 1),\left(\frac{1}{2} x, 0\right)\right), d\left((y, 1),\left(\frac{1}{2} y, 0\right)\right)\right\}-1\right\} \\
& =\max \left\{d((x, 1),(y, 1)),\left\{d\left((x, 1),\left(\frac{1}{2} x, 0\right)\right)\right\}-1\right\} \\
& \leq \max \left\{d((x, 1),(y, 1)),\left\{d\left((x, 1),\left(\frac{1}{2} x, 0\right)\right)\right\}\right\} \\
& =d\left((x, 1),\left(\frac{1}{2} x, 0\right)\right) .
\end{aligned}
$$

Also we consider

$$
\begin{aligned}
\varphi(d((x, 1), T(x, 1))) & \leq \frac{1}{2} d((x, 1), T(x, 1))=\frac{1}{2} d\left((x, 1),\left(\frac{x}{2}, 0\right)\right) \leq 2 d\left((x, 1),\left(\frac{x}{2}, 0\right)\right) \\
& \leq 2\left(d((x, 1),(y, 1))+d\left((y, 1),\left(\frac{x}{2}, 0\right)\right)\right) \leq 2\left(d((x, 1),(y, 1))+d\left(\left(\frac{x}{2}, 1\right),\left(\frac{x}{2}, 0\right)\right)\right) \\
& =2 d((x, 1),(y, 1))+2 d(A, B) .
\end{aligned}
$$

Hence $\varphi(d((x, 1), T(x, 1)))-2 d(A, B) \leq 2 d((x, 1),(y, 1))=\alpha((x, 1),(y, 1)) d((x, 1),(y, 1))$. By (1), it follows that

$$
\begin{aligned}
\frac{1}{4} \sqrt{(x-y)^{2}} & =\phi(d((T(x, 1), T(y, 1)))) \leq \alpha((x, 1),(y, 1)) \phi(d((T(x, 1), T(y, 1)))) \\
& \leq \beta(\phi(M((x, 1),(y, 1)))) \phi(\max \{d((x, 1),(y, 1)), \max \{m((x, 1),(y, 1))\}-d(A, B)\}) \\
& <\phi(\max \{d((x, 1),(y, 1)), \max \{m((x, 1),(y, 1))\}-d(A, B)\}) \\
& =\phi\left(d\left((x, 1),\left(\frac{1}{2} x, 0\right)\right)\right)=\frac{\sqrt{\frac{1}{4} x^{2}+1}}{1+\sqrt{\frac{1}{4} x^{2}+1}} .
\end{aligned}
$$

Therefore, $T$ is a modified Suzuki-Edelstein-Geraghty proximal contraction mapping. The point $(0,1) \in$ $A_{0}$ is the unique best proximity point of $T$.

If $\phi(t)=t$ for all $t \geq 0$, in Theorem 3 , we have the following corollary.

Corollary 1. Suppose that $A$ and $B$ are two non-empty closed subsets of a complete metric space $(X, d)$ with $A_{0}$ is non-empty. Assume that $\alpha: A \times A \rightarrow[0, \infty)$ is a function and there exists $\beta \in \mathcal{F}$. If $T: A \rightarrow B$ be a non self-mapping such that for all $x, y \in A, \varphi(d(x, T x))-2 d(A, B) \leq \alpha(x, y) d(x, y)$ implies $\alpha(x, y) d(T x, T y) \leq$ $\beta(M(x, y)) \max \{d(x, y), m(x, y)-d(A, B)\}$, where $M(x, y)=\max \{d(x, y), d(x, T x), d(y, T y)\}, \quad m(x, y)=$ $\max \{d(x, T x), d(y, T y)\}$ and $\varphi \in \Phi_{\varphi}$ with the following conditions hold:

1. $T\left(A_{0}\right) \subseteq B_{0}$ and the pair $(A, B)$ satisfies the weak P-property,

2. $T$ is triangular $\alpha$-proximal admissible with respect to $\eta(x, y)=2$,

3. $T$ is continuous,

4. there exist $x_{0}, x_{1} \in A$ such that $d\left(x_{1}, T x_{0}\right)=d(A, B)$ and $\alpha\left(x_{0}, x_{1}\right) \geq 2$,

then $T$ has a unique best proximity point in $A_{0}$.

We can prove the existence and uniqueness of best proximity point by replacing the continuity assumption with RJ-property in Theorem 3. 
Theorem 4. Let $(X, d)$ be a complete metric space and $A$ and $B$ be non-empty closed subsets of $X$ with $A_{0}$ is non-empty. If $T: A \rightarrow B$ be a modified Suzuki-Edelstein-Geraghty proximal contraction mapping such that the following conditions hold:

1. $T\left(A_{0}\right) \subseteq B_{0}$ and the pair $(A, B)$ satisfies the weak P-property,

2. $T$ is triangular $\alpha$-proximal admissible with respect to $\eta(x, y)=2$,

3. Thas the RJ-property and assume that $\alpha(x, y) \geq 2$ for all $x, y \in A$,

4. there exist $x_{0}, x_{1} \in A$ such that $d\left(x_{1}, T x_{0}\right)=d(A, B)$ and $\alpha\left(x_{0}, x_{1}\right) \geq 2$,

then $T$ has a unique best proximity point in $A_{0}$.

Proof. From the proof of Theorem 3, $\left\{x_{n}\right\}$ is cauchy such that $x_{n} \rightarrow x * \in A$ as $n \rightarrow \infty$. Since $T$ has the RJ-property $x^{*} \in A_{0}$. We shall prove that $d\left(x^{*}, T x^{*}\right)=d(A, B)$. From the proof of Theorem 3 , we have $d\left(x_{n+1}, x_{n+2}\right) \leq d\left(x_{n}, x_{n+1}\right)$ for all $n \in \mathbb{N} \cup\{0\}$.

Suppose $d\left(x_{n}, x^{*}\right)<\frac{1}{2} d\left(x_{n}, x_{n+1}\right)$ and $d\left(x_{n+1}, x^{*}\right)<\frac{1}{2} d\left(x_{n+1}, x_{n+2}\right)$, for some $n \in \mathbb{N}$. Therefore,

$$
\begin{aligned}
d\left(x_{n}, x_{n+1}\right) & \leq d\left(x_{n}, x^{*}\right)+d\left(x^{*}, x_{n+1}\right)<\frac{1}{2} d\left(x_{n}, x_{n+1}\right)+\frac{1}{2} d\left(x_{n+1}, x_{n+2}\right) \\
& \leq \frac{1}{2} d\left(x_{n}, x_{n+1}\right)+\frac{1}{2} d\left(x_{n}, x_{n+1}\right)=d\left(x_{n}, x_{n+1}\right)
\end{aligned}
$$

a contradiction. Hence $d\left(x_{n}, x^{*}\right) \geq \frac{1}{2} d\left(x_{n}, x_{n+1}\right)$ and $d\left(x_{n+1}, x^{*}\right) \geq \frac{1}{2} d\left(x_{n+1}, x_{n+2}\right)$, for all $n \in \mathbb{N}$.

Now, we consider

$$
\begin{aligned}
\varphi\left(d\left(x_{n}, T x_{n}\right)\right) & \leq \frac{1}{2} d\left(x_{n}, T x_{n}\right) \leq d\left(x_{n}, T x_{n}\right) \leq d\left(x_{n}, x_{n+1}\right)+d\left(x_{n+1}, T x_{n}\right) \\
& \leq 2 d\left(x_{n}, x^{*}\right)+d(A, B) \leq 2 d\left(x_{n}, x^{*}\right)+2 d(A, B) .
\end{aligned}
$$

From the above inequality, we obtain

$$
\varphi\left(d\left(x_{n}, T x_{n}\right)\right)-2 d(A, B) \leq 2 d\left(x_{n}, x^{*}\right) \leq \alpha\left(x_{n}, x^{*}\right) d\left(x_{n}, x^{*}\right) .
$$

Since $x_{n} \in A \forall n \in \mathbb{N}$ and $x^{*} \in A$, we obtain $\alpha\left(x_{n}, x^{*}\right) \geq 2$. Thus from (1), it follows that

$$
\begin{aligned}
\phi\left(d\left(T x_{n}, T x^{*}\right)\right) & \leq \alpha\left(x_{n}, x^{*}\right) \phi\left(d\left(T x_{n}, T x^{*}\right)\right) \\
& \leq \beta\left(\phi\left(M\left(x_{n}, x^{*}\right)\right)\right) \phi\left(\max \left\{d\left(x_{n}, x^{*}\right), m\left(x_{n}, x^{*}\right)-d(A, B)\right\}\right) \\
& <\phi\left(\max \left\{d\left(x_{n}, x^{*}\right), \max \left\{m\left(x_{n}, x^{*}\right)\right\}-d(A, B)\right\}\right) \\
& \leq \phi\left(\max \left\{d\left(x_{n}, x^{*}\right), \max \left\{d\left(x_{n}, x_{n+1}\right)+d\left(x_{n+1} T x_{n}\right), d\left(x^{*}, T x^{*}\right)\right\}-d(A, B)\right\}\right) \\
& =\phi\left(\max \left\{d\left(x_{n}, x^{*}\right), \max \left\{d\left(x_{n}, x_{n+1}\right), d\left(x^{*}, T x^{*}\right)-d(A, B)\right\}\right\}\right) .
\end{aligned}
$$

Letting $n \rightarrow \infty$ in (22), we obtain

$$
\phi\left(\lim _{n \rightarrow \infty} d\left(T x_{n}, T x^{*}\right)\right)<\phi\left(d\left(x^{*}, T x^{*}\right)-d(A, B)\right) .
$$

Since $d\left(x^{*}, T x^{*}\right) \leq d\left(x^{*}, x_{n+1}\right)+d\left(x_{n+1}, T x_{n}\right)+d\left(T x_{n}, T x^{*}\right)$, we get

$$
d\left(x^{*}, T x^{*}\right)-d\left(x_{n+1}, T x_{n}\right) \leq d\left(x^{*}, x_{n+1}\right)+d\left(T x_{n}, T x^{*}\right) .
$$

From the property of $\phi$, it follows that

$$
\phi\left(d\left(x^{*}, T x^{*}\right)-d\left(x_{n+1}, T x_{n}\right)\right) \leq \phi\left(d\left(x^{*}, x_{n+1}\right)+d\left(T x_{n}, T x^{*}\right)\right) .
$$

Hence

$$
\phi\left(d\left(x^{*}, T x^{*}\right)-d(A, B)\right) \leq \phi\left(\lim _{n \rightarrow \infty} d\left(T x_{n}, T x^{*}\right)\right) .
$$


By (23) and (24), we have

$$
\phi\left(d\left(x^{*}, T x^{*}\right)-d(A, B)\right) \leq \phi\left(\lim _{n \rightarrow \infty} d\left(T x_{n}, T x^{*}\right)\right)<\phi\left(d\left(x^{*}, T x^{*}\right)-d(A, B)\right),
$$

a contradiction. Hence $d\left(x^{*}, T x^{*}\right)=d(A, B)$. Therefore, $x^{*}$ is the best proximity point of $T$. Uniqueness follows from the proof of Theorem 3 .

If we take $\phi(t)=t$ for all $t \geq 0$, in Theorem 4 , we have the following corollary.

Corollary 2. Suppose that $A$ and $B$ are two non-empty closed subsets of a complete metric space $(X, d)$ with $A_{0}$ is non-empty. Further suppose that $\alpha: A \times A \rightarrow[0, \infty)$ is a function and there exists $\beta \in \mathcal{F}$. If $T: A \rightarrow B$ be a non self-mapping such that for all $x, y \in A$, we have $\varphi(d(x, T x))-2 d(A, B) \leq \alpha(x, y) d(x, y)$ implies $\alpha(x, y) d(T x, T y) \leq$ $\beta(M(x, y)) \max \{d(x, y), m(x, y)-d(A, B)\}$, where $M(x, y)=\max \{d(x, y), d(x, T x), d(y, T y)\}, \quad m(x, y)=$ $\max \{d(x, T x), d(y, T y)\}$ and $\varphi \in \Phi_{\varphi}$, with the following conditions hold:

1. $T\left(A_{0}\right) \subseteq B_{0}$ and the pair $(A, B)$ satisfies the weak P-property,

2. $T$ is triangular $\alpha$-proximal admissible with respect to $\eta(x, y)=2$,

3. $T$ has the RJ-property and assume that $\alpha(x, y) \geq 2$ for all $x, y \in A$,

4. there exist $x_{0}, x_{1} \in A$ such that $d\left(x_{1}, T x_{0}\right)=d(A, B)$ and $\alpha\left(x_{0}, x_{1}\right) \geq 2$,

then $T$ has a unique best proximity point in $A_{0}$.

Conflicts of Interest: "The author declares no conflict of interest."

\section{References}

[1] Banach, S. (1922). Sur les opérations dans les ensembles abstraits et leur application aux équations intégrales. Fundamenta Mathematicae, 3(1), 133-181.

[2] Edelstein, M. (1961). An extension of Banach's contraction principle. Proceedings of the American Mathematical Society, 12(1), 7-10.

[3] Geraghty, M. A. (1973). On contractive mappings. Proceedings of the American Mathematical Society, 40(2), 604-608.

[4] Suzuki, T. (2008). A generalized Banach contraction principle that characterizes metric completeness. Proceedings of the American mathematical Society, 136(5), 1861-1869.

[5] Abkar, A., \& Gabeleh, M. (2012). Global optimal solutions of noncyclic mappings in metric spaces. Journal of Optimization Theory and Applications, 153(2), 298-305.

[6] Abkar, A., \& Gabeleh, M. (2013). Best proximity points of non-self mappings. TOP, 21(2), 287-295.

[7] Al-Thagafi, M. A., \& Shahzad, N. (2009). Convergence and existence results for best proximity points. Nonlinear Analysis: Theory, Methods \& Applications, 70(10), 3665-3671.

[8] Basha, S. S. (2011). Best proximity points: optimal solutions. Journal of Optimization Theory and Applications, 151(1), 210-216.

[9] Basha, S. S. (2012). Discrete optimization in partially ordered sets. Journal of Global Optimization, 54(3), 511-517.

[10] Jleli, M., \& Samet, B. (2013). Best proximity points for $\alpha-\psi$-proximal contractive type mappings and applications. Bulletin des Sciences Mathématiques, 137(8), 977-995.

[11] Kumam, P., Salimi, P., \& Vetro, C. (2014). Best proximity point results for modified $\alpha$-proximal C-contraction mappings. Fixed Point Theory and Applications, 2014(1), Article No. 99.

[12] Zhang, J., Su, Y., \& Cheng, Q. (2013). A note on 'A best proximity point theorem for Geraghty-contractions'. Fixed Point Theory and Applications, 2013(1), Article No. 99.

[13] Hamzehnejadi, J., \& Lashkaripour, R. (2016). Best proximity points for generalized $\alpha-\phi$-Geraghty proximal contraction mappings and its applications. Fixed Point Theory and Applications, 2016(1), Article No. 72.

[14] Hussain, A., Iqbal, M. Q., \& Hussain, N. (2019). Best proximity point results for Suzuki-Edelstein proximal contractions via auxiliary functions. Filomat, 33(2), 435-447.

[15] Babu, G. V. R., \& Sailaja, P. D. (2012). A fixed point theorem of generalized weakly contractive maps in orbitally complete metric spaces. Thai Journal of Mathematics, 9(1), 1-10. 
(C) 2020 by the authors; licensee PSRP, Lahore, Pakistan. This article is an open access article distributed under the terms and conditions of the Creative Commons Attribution (CC-BY) license (http://creativecommons.org/licenses/by/4.0/). 